\title{
Developmental disorders of the enteric nervous system
}

\author{
R P Kapur
}

Primary developmental disorders of the human enteric nervous system can be grouped into those characterised by an abnormal number of neurones (hyperganglionosis, hypoganglionosis, aganglionosis) versus abnormal differentiation of neurones (biochemical and/or physiological). ${ }^{1}$ In each case, the clinical presentation may be similar with a predominance of obstructive symptoms. Comprehensive evaluation of such patients usually involves histopathological studies of a rectal biopsy. However, objective criteria necessary to define and diagnose many enteric dysganglionoses are poorly established or impractical to implement. As a consequence, intestinal aganglionosis and some forms of intestinal hyperganglionosis (for example, MEN2B) may be the only developmental disorders of enteric neurodevelopment that are consistently recognised by most paediatric pathologists. Enteric neurones can also be impaired secondarily by constitutive metabolic defects (for example, lysosomal storage disorders) or acquired forms of injury (for example, ischaemia) but only primary enteric dysganglionoses will be considered in this paper.

\section{Intestinal aganglionosis}

Congenital intestinal aganglionosis (Hirschsprung disease, HSCR) is characterised by complete absence of ganglion cells in the submucosal and myenteric plexi. Diagnosis is usually established by histological analysis of suction rectal biopsies that sample small amounts of rectal submucosa (fig 1). Although the sensitivity and specificity of this approach are generally high, reliability depends a great deal on the quality of the biopsy, number of sections examined, and experience of the pathologist. ${ }^{2}$ The normal sparse distribution of submucosal ganglia necessitates correct sampling and evaluation of multiple tissue sections to avoid an erroneous diagnosis of aganglionosis. An ancillary finding that is present in most, but not all, positive biopsies is hypertrophic submucosal nerves which represent projections from extrinsic nerve fibres. Projections from these nerves into the muscularis mucosa and lamina propria can be demonstrated with acetylcholinesterase enzyme histochemistry or other markers, which facilitate diagnosis in equivocal cases. A physiological zone of aganglionosis exists in the terminal $1-3 \mathrm{~cm}$ of the rectum and renders biopsies from this area inappropriate to exclude HSCR. ${ }^{3}$ Unfortunately, efforts to obtain biopsies proximal to this zone may "miss" a very short segment of clinically significant aganglionosis. ${ }^{4}$ For all of these reasons, the development of alternative methods of diagnosis should be encouraged.

The pathogenesis of intestinal aganglionosis involves failure of neural crest derived neuronal precursors to colonise the entire gastrointestinal tract during embryogenesis. This phenotype is associated with mutations in any one of eight different genes, which can be organised into three groups (table 1). Each group appears to affect different stages of the colonisation process, despite considerable similarities in ultimate outcome. In almost every case, mutations in murine homologues are also associated with intestinal aganglionosis, such that mouse models are a valuable resource for investigators in this field.

\section{Hyperganglionosis}

Intestinal dysmotility is occasionally associated with increased numbers of ganglion cells in enteric plexi or ectopically in the lamina propria. Two distinct patterns of hyperganglionosis have been reported.

(1) Ganglioneuromas, nodular proliferations of ganglion cells and abundant nerve fibres with associated glia, have been described as solitary or diffuse lesions. ${ }^{12}$ Diffuse ganglioneuromatosis is almost always associated with multiple endocrine neoplasia type 2B (MEN2B), a heritable disorder due to M918T missense mutation in the RET protooncogene. Ganglioneuromas may exist in the enteric plexi or ectopically. ${ }^{13}$

(2) Intestinal neuronal dysplasia (IND) is a highly controversial entity, in part because it has been so poorly and inconsistently defined by various groups. One of the most consistently described histological features is increased density of submucosal ganglia ("hyperganglionosis") and increased numbers of ganglion cells per submucosal ganglion ("giant ganglia"). These findings, occasionally in conjunction with other changes (for example, ectopic ganglia, HSCR-like acetylcholinesterase pattern, increased prominence of submucosal innervation), have been observed in a variety of clinical contexts including the transitional zone between ganglionic and aganglionic gut in HSCR patients, proximal to various obstructive lesions, and in patients with idiopathic pseudo-obstruction. However, all of the criteria used to define IND have been questioned in various studies and many believe that the changes are either within the spectrum of normal or secondary events that have no clinical significance. ${ }^{14}$

The controversy that surrounds IND illustrates the subjective nature of contemporary interpretation of intestinal biopsies, lack of universally accepted and easily applied methods to quantify ganglion cells, and the need for

Abbreviations used in this paper: $\mathrm{HSCR}$,

Hirschsprung disease; IND, intestinal neuronal dysplasia. kapur@washington.edu 


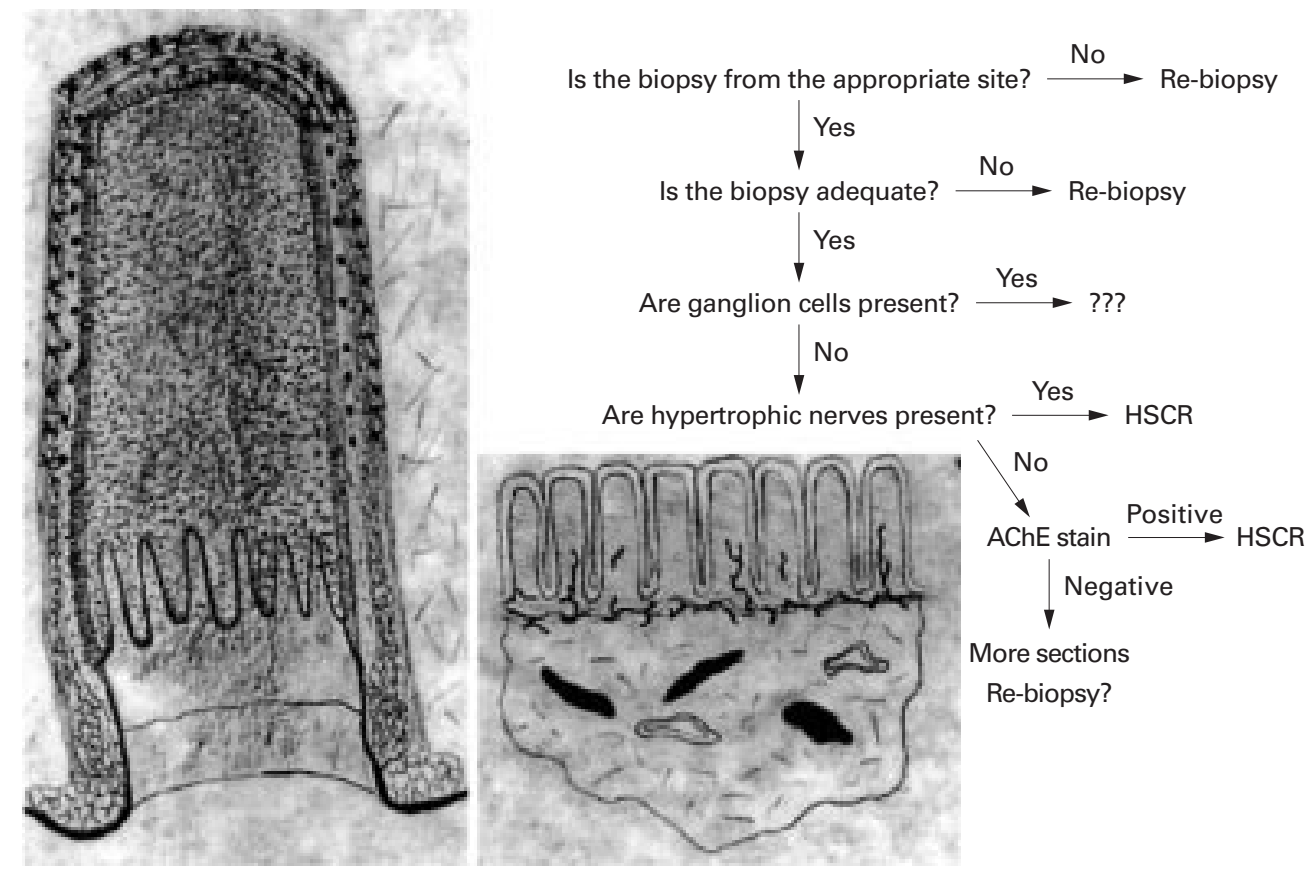

Figure 1 Histological diagnosis of Hirschsprung disease (HSCR). AChE, acetylcholinesterase enzyme.

better clinical-pathological correlation in this field. At present, it seems prudent to regard IND as an "investigational phenotype" that needs further study. Mice that carry mutations in the Hox11L1 (also termed Enx or Ncx) gene were offered as a putative model for IND because they suffer from intestinal pseudoobstruction and have increased numbers of large intestinal myenteric ganglion cells. ${ }^{15} 16$ However, no data concerning diagnostic criteria used to define IND in humans have been reported in mice, and hence their suitability as a model is unclear.

\section{Hypoganglionosis}

Intestinal pseudo-obstruction has been associated with reduced numbers of ganglion cells in several clinical contexts. ${ }^{17}$ The most common example may be the transitional zone between ganglionic and aganglionic colon in HSCR patients. This zone is characterised by a variable length of gut with abnormal numbers of ganglia and/or ganglion cells. In some patients, hyperganglionosis (see IND) may be evident. However, a reduced density of myenteric ganglia is more characteristic of the transitional zone. Although many believe that inadequate resection of a hypoganglionic transitional zone may account for symptoms that persist after surgery, this hypothesis has not been evaluated objectively.
Isolated hypoganglionosis without aganglionosis has also been reported as a primary cause of intestinal pseudo-obstruction. It is not clear if such cases represent the forme-fruste of HSCR disease or result from different pathogenic mechanisms. It is likely that both alternatives are true. Obstructive symptoms, hypoganglionosis, and identical HSCR gene mutations have been described in relatives of HSCR patients. In addition, application of silver staining techniques to biopsies from diverse groups of pseudo-obstruction patients has revealed reductions in subsets of ganglion cells that are often not appreciated by light microscopy. ${ }^{18}$ Similarly, various murine models have been described in which one or more specific subtype of enteric neurone fails to develop. ${ }^{19}$

Hypoganglionosis is almost impossible to diagnose based on submucosal biopsies because the normal distribution and size of submucosal ganglia are so small. With the exception of a few specialised laboratories, the contemporary histopathological approach to intestinal biopsies from patients with motility disorders is based primarily on light microscopic evaluation of haematoxylin-eosin stained sections. The resolution of this method is limited to relatively major changes in ganglion cell number/distribution. Even with full thickness biopsies, recognition of mild or

Table 1 Genes associated with intestinal aganglionosis

\begin{tabular}{|c|c|c|c|c|c|}
\hline Gene & Product & Species & Transmission & Frequency in Hirschsprung patients & $\operatorname{Ref}^{\star}$ \\
\hline RET & Co-receptor for GDNF & $\mathrm{Mo}, \mathrm{Hu}$ & $\mathrm{AD}$ & $20-25 \%$ (40-70\% in long segment) & Chakravarti $^{5}$ \\
\hline GDNF & Ligand for RET & $\mathrm{Mo}, \mathrm{Hu}$ & $\mathrm{AD}$ & Unknown, but probably rare & Hofstra et $a l^{6}$ \\
\hline GFR $\alpha 1$ & Co-receptor for GDNF & Mo & $\mathrm{AR}$ (mouse) & Not significant in humans & $\begin{array}{l}\text { Angrist et } a l^{7} \\
\text { Myers et al }\end{array}$ \\
\hline NTN & Ligand for RET & $\mathrm{Hu}$ & $\mathrm{AD} ?$ & Single family reported & Doray et al ${ }^{9}$ \\
\hline EDNRB & Receptor for ET3 & $\mathrm{Mo}, \mathrm{Ra}, \mathrm{Hu}$ & $\mathrm{AD}$ or $\mathrm{AR}$ & $5-10 \%$ & Angrist $e t a l^{7}$ \\
\hline EDN3 & Ligand for ETB & $\mathrm{Mo}, \mathrm{Hu}$ & $\mathrm{AD}$ or $\mathrm{AR}$ & $5-10 \%$ & Angrist et al \\
\hline ECE-1 & ET3 converting enzyme & $\mathrm{Mo}, \mathrm{Hu}$ & AR & Rare & Hofstra et $a l^{10}$ \\
\hline Sox 10 & Transcription factor & $\mathrm{Mo}, \mathrm{Hu}$ & $\mathrm{AD}$ & $<5 \%$ (limited data available) & Pingault et $a l^{11}$ \\
\hline
\end{tabular}

^See main reference list. 
moderate hypoganglionosis is difficult as ganglion cell density varies with age, site, and handling (fixative, stretching, etc.). Subtle, but potentially significant, alterations in specific subtypes of enteric neurones can only be resolved with more sophisticated methods (for example, silver staining, immunohistochemistry, electrophysiology) that are costly and may be impractical with current medical economic constraints. The relative rarity and probable heterogeneous nature of enteric dysganglionoses reduces the likelihood that a battery of specialised tests will be adopted widely, and supports the need for centralised referral centres that will combine research and clinical services.

1 Kapur RP. Hirschsprung disease and other enteric dysganglionoses. Crit Rev Clin Lab Sci 1999;36:225-73.

2 QualmanSJ, Pysher T, Schauer G. Hirschprung disease: differential diagnosis and sequelae. Perspect Pediatr Pathol 1997;20:111-26.

3 Weinberg AG. Hirschsprung's disease-a pathologist's view. Perspect Pediatr Pathol 1975;2:207-39.

4 Ballard ET. Ultrashort segment Hirschsprung's disease: a case report. Pediatr Pathol Lab Med 1996;16:319-25.

5 Chakravarti A. Endothelin receptor-mediated signaling in Hirschsprung disease. Hum Molec Genet 1996;5:303-7.

6 Hofstra RMW, Osinga J, Buys CHCM. Mutations in Hirschsprung disease: when does a mutation contribute to the phenotype. Eur $\mathcal{F}$ Hum Genet 1997;5:180-5.

7 Angrist M, Jing S, Bolk S, et al. Human GFRA1: cloning, mapping, genomic structure and evaluation as a candidate
8 Myers SM, Salomon G, Goessling A, et al. Investigation of germline GFR alpha-1 mutations in Hirschsprung disease. $\underset{\Im}{\text { germline GFR alpha-1 mutation }}$ - $1999 ; 36: 217-20$.

9 Doray B, Salomen R, Amiel J, et al. Mutations of the RET ligand, neurturin, supports multigenic inheritance in Hirschsprung disease. Hum Mol Genet 1998;7:1449-14

10 Hofstra RMW, Valdenaire O, Arch E, et al. A loss-offunction mutation in the endothelin-converting enzyme 1 (ECE-1) associated with Hirschsprung disease, cardiac defects and autonomic dysfunction. Am 7 Hum Genet 1999;64:304-8.

11 Pingault V, Bondurand $\mathrm{N}$, Kuhlbrodt $\mathrm{K}$, et al. SOX10 mutations in patients with Waardenburg-Hirschsprung disease. Nat Genet 1998;18:171-3.

12 Shekitka KM, Sobin LH. Ganglioneuromas of the gastrointestinal tract. Relation to von Recklinghausen disease and other multiple tumor syndromes. Am f Surg Pathol 1994;18:250-7.

13 Carlson KM, Dou S, Chi D, et al. Single missense mutation in the tyrosine kinase catalytic domain of the RET protooncogene is associated with multiple endocrine neoplasia type 2B genesis. Development 1993;119:1005-17.

14 Cord-Udy CL, Smith VV, Abmed S, et al. An evaluation of the role of suction rectal biopsy in the diagnosis of intestinal neuronal dysplasia. $\mathcal{F}$ Pediatr Gastroenterol Nutr 1997;24: nal n.

15 Hatano M, Aoli T, Dezawa M, et al. A novel pathogenesis of megacolon in Ncx/Hox $11 \mathrm{~L} .1$ deficient mice. 7 Clin Invest megacolon in Ncx/H

16 Shirasawa S, Ynker AMR, Roth KA, et al. Enx (Hox 11L1)deficient mice develop myenteric neuronal hyperplasia and megacolon. Nat Med 1997;3:646-50.

17 Meier-Ruge WA, Brunner LA, Engert J, et al. A correlative morphometric and clinical investigation of hypoganglionosis of the colon in children. Eur F Pediatr Surg 1999;9:6774

18 Krishnamurthy S, Heng Y, Schuffler MD. Chronic intestinal pseudo-obstruction in infants and children caused by diverse abnormalities of the myenteric plexus. Gastroenterology 1993;104:1398-408.

19 Gershon MD. The second brain. New York: Harper Collins, 1993. 